\title{
The Potential of Minjingu Phosphate Rock for Water Defluoridation
}

\author{
Francisco Lucas Olambo ${ }^{1}$, Joseph Yoeza Naimani Philip" ${ }^{2,}$, James Epiphan Gabriel Mdoe ${ }^{2}$ \\ ${ }^{1}$ Tanzania Industrial Research and Development Organization, Dar es Salaam, Tanzania \\ ${ }^{2}$ Chemistry Department, University of Dar es Salaam, Dar es Salaam, Tanzania
}

Email address:

olambof@yahoo.com (F. L. Olambo), jynphilip@udsm.ac.tz (J. Y. N. Philip), mdoej@udsm.ac.tz (J. E. G. Mdoe)

To cite this article:

Francisco Lucas Olambo, Joseph Yoeza Naimani Philip, James Epiphan Gabriel Mdoe. The Potential of Minjingu Phosphate Rock for Water Defluoridation. International Journal of Science, Technology and Society. Vol. 4, No. 1, 2016, pp. 1-6. doi: 10.11648/j.ijsts.20160401.11

\begin{abstract}
In some parts of Tanzania, fluoride ion concentrations in potable water are higher than recommended by WHO. Consequently, searches for economically and technically viable strategies are required to address this problem. This work aims to determine the potential of phosphate rock mined from Minjingu area in Northern Tanzania as water de-fluoridatant. The results obtained are reported herein. The rock particles were chemically activated and then characterised by XRF, XRD and nitrogen physisorption. Results showed that the main component of chemically activated rock particles was calcium hydroxyapatite with $\mathrm{Ca} / \mathrm{P}$ ratio of 1.55 whereas the main component of non-activated particles was calcium fluoroapatite $(\mathrm{Ca} / \mathrm{P}$ ratio of 1.66$)$. The results also indicated that activated rock material was mesoporous with a BET surface area of $57.4 \mathrm{~m}^{2} / \mathrm{g}$. Results for water defluoridation showed that the material had a fluoride ion percentage removal of about $90 \%$, when the adsorbent dose was $8 \mathrm{~g}$, contact time of 30 minutes, initial fluoride ion concentration $5 \mathrm{mg} / \mathrm{L}$, pH values of 6.0 to 7.2 and batch volume of $50 \mathrm{~mL}$. The material could be regenerated using $1 \% \mathrm{NaOH}$ and reused in the water defluoridation process. Therefore, Minjingu Phosphate Rock (MPR) is potential water de-fluoridatant.
\end{abstract}

Keywords: Water Defluoridation, Minjingu Phosphate Rock, Potable Water, Adsorption-Desorption Isotherms, Tanzania

\section{Introduction}

People obtain water from various sources including rain, surface water (lakes, rivers and ponds) and groundwater (boreholes, springs). As reported elsewhere [1], groundwater is the main source of water in Tanzanian rural areas especially in Dodoma, Arusha, Shinyanga, Kilimanjaro, Singida, and recently in the city of Dar es Salaam. It is well known that groundwater contains dissolved gases and minerals, including fluoride salts. Some parts of the earth's crust contain minerals with high levels of fluoride ion. When groundwater is in contact with these minerals, soluble fluoride salts dissolve, thus releasing fluoride ions in water [2].

Fluoride in potable water (water for food preparation and drinking) can either be advantageous or disadvantageous to human health depending on its concentration level. In areas where the levels of fluoride ion in water is less than $1.5 \mathrm{mg} / \mathrm{L}$, potable water is fluoridated to the level that prevents tooth decay, and is recommended by WHO [3, 4]. However, fluoride concentrations ranging from $1.5-10 \mathrm{mg} / \mathrm{L}$ may cause either dental, skeletal or crippling fluorosis [5]. Many people from rural areas in Arusha, Kilimanjaro, Singida and Shinyanga use water with fluoride ions concentrations greater than $1.5 \mathrm{mg} / \mathrm{L}$ for drinking and food preparation $[6,7]$. It is reported in the literature [8] that fluoride concentrations in groundwater from some parts of Tanzania may be up to 17 $\mathrm{mg} / \mathrm{L}$ (Shinyanga), $21.3 \mathrm{mg} / \mathrm{L}$ (Singida), $32 \mathrm{mg} / \mathrm{L}$ (Arusha) and $46 \mathrm{mg} / \mathrm{L}$ (Manyara). It was also reported elsewhere that $87.4 \%$ of children aged between 9 and 13 at Maji ya Chai Meru, Tanzania were found to have severe dental and skeletal fluorosis [7].

A number of defluoridation methods have been tested at the Ngurdoto Defluoridation Research Station (NDRS) in Arusha and elsewhere. The well-studied defluoridation methods using adsorbent materials and precipitation include Nalgonda, activated clay, activated alumina and bone char [1, $7,9,10,11]$. Each of these defluoridation techniques have one or more setbacks including the need for high chemical doses, large amounts of sludge, not locally available in Tanzania, slow and low fluoride removal and ethical rejections [8, 11-15]. Other reported methods involve electrolytic techniques and ion exchange [16, 17], which 
seems to be expensive to developing countries such as Tanzania. Defluoridation technique is required to have a modest investment, low maintenance cost, should use a simple design which can be operated by villagers and able to reduce fluoride content to acceptable levels. The use of phosphate rock in water defluoridation is one of the methods envisaged to meet these requirements, because calcium apatite is the major constituent of the phosphate rock. The challenge of using phosphate rock, however, is that it is obtained as impure calcium hydroxyapatite. Consequently, there is a need to activate the raw phosphate rock with the aim of dissociating carbonates and removing organic matter and halogens, as well as improving porosity. Therefore, as a strategy in providing defluoridated water at affordable costs, it is proposed in this study to use the activated Minjingu phosphate rock for water defluoridation.

\section{Experimental}

\subsection{Materials and Reagents}

Minjingu Phosphate Rock (MPR) was obtained from phosphate rock mining site at Minjingu Mining and Fertilizer Company in Manyara, Tanzania. Sodium hydroxide, glacial acetic acid, anhydrous sodium fluoride, sodium chloride, sodium citrate, cyclohexanediaminetetraacetic acid (CDTA), hydrochloric acid and Whatmann filter papers were purchased from Sigma Aldrich Company. Chemicals were used as purchased.

\subsection{Activation of MPR}

MPR was crushed into powder and washed with distilled water. The air dried MPR was sifted via number BS 410 sieve with aperture size of $0.2 \mathrm{~mm}$. The activation process involved chemical and thermal activation. One portion of MPR powder $(100 \mathrm{~g})$ was left as non-activated MPR (naMPR). The second portion (100 g) was chemically activated (caMPR) by soaking in $1 \mathrm{~L}$ of $1 \% \mathrm{NaOH}$ and agitated using Digital Grant Bio Shaker HY-51 machine overnight, and then washed thoroughly with distilled water before air drying. The third portion was thermally activated (taMPR) in a muffle furnace (model $\mathrm{F} 46120 \mathrm{CM}$ ) at a temperature of $800^{\circ} \mathrm{C}$ for 120 minutes then left to cool. The fourth portion was thermally activated as for portion three followed by chemical activation as for portion two (tcaMPR). The fifth portion was chemically activated as portion two followed by thermal activation as for portion three (ctaMPR). Finally all samples were stored in a desiccator.

\subsection{Characterization of MPR}

X-Ray Diffraction (XRD) patterns were obtained using InXiTU Material diffractometer (model BTX 231) connected to a Lap top computer (model HP 530) which was installed with InXiTU BTX Interface software. In a typical procedure MPR was ground to a powder with particle size less than 150 $\mu \mathrm{m}$ and packed into an aluminium holder, which was then placed in goniometer and bombarded with X-rays generated from cobalt tubes. The XRD was operated at $30.3 \mathrm{kV}, 30 \mathrm{~mA}$ and $2 \Theta$ range from $5^{\circ}-54^{\circ}$.

$\mathrm{X}$-Ray Fluorescence (XRF) investigations of activated and non-activated MPR were carried out using Bruker XRF Spectrometer (Model S8 Tiger). In a typical procedure the samples were crushed and ground into a fine powder. The powdered samples were then compressed under a pressure of $200 \mathrm{kN}$ to form circular pellets with a diameter of $34 \mathrm{~mm}$. The tablets were placed in aluminium cups, and the cups were placed in the XRF spectrometer. Boric acid was used for holding and labeling the pellets. The pellets were then qualitatively and quantitatively measured and analyzed to determine the elemental and percentage composition of chemically activated and non-activated MPR.

The surface area, pore size, pore size distribution and pore volume of naMPR, taMPR, caMPR, tcaMPR and ctaMPR were determined through nitrogen adsorption-desorption measurement at $77.35 \mathrm{~K}$ using an automated gas sorption analyzer, Quantachrome NovaWin version 11.03. The sample weight in each experiment was $0.0701 \mathrm{~g}$. The surface area was calculated according to the Brunaeur-Emmet-Teller (BET) method while pore size distribution was found using Barrett-Joyner-Halender (BJH) method.

\subsection{Measurement of Fluoride Ion Concentration in Water}

Two fluoride electrodes were used to analyse fluoride in the water samples. One of the electrodes was a fluoride-sensing radiometer F1 052 while the second was a single-junction reference electrode, with sleeve type diaphragm connected to a jenway potentiometer (Ion meter model 3205). Reference standards were made from serial dilutions of a stock solution of sodium fluoride (NaF) $1000 \mathrm{mg} / \mathrm{L}$. A stock solution of sodium fluoride $(\mathrm{NaF}) 1000 \mathrm{mg} / \mathrm{L}$ was prepared by measuring $2.210 \mathrm{~g}$ of $\mathrm{NaF}$ and dissolved in $1 \mathrm{~L}$ of distilled water. Total Ion Strength Adjusting Buffer (TISAB II) solution was prepared by mixing 4 $\mathrm{g}$ of cyclohexylenediaminetetraacetic acid (CDTA) with glacial acetic acid $(60 \mathrm{~mL})$ and $\mathrm{NaOH}(58 \mathrm{~g})$ in distilled water $(500$ $\mathrm{mL}$ ), and $\mathrm{pH}$ adjusted to between 5.3 and $5.5 \mathrm{pH}$ by adding $5 \mathrm{M}$ $\mathrm{NaOH}$ solution drop wise followed by dilution to $1 \mathrm{~L}$ with distilled water. A water sample of $15 \mathrm{~mL}$ was transferred into a plastic container by means of a pipette followed by $15 \mathrm{~mL}$ of TISAB II. The electrodes were immersed into the sample and the concentration of fluoride ions was recorded. The measurements were performed in triplicate.

\subsection{Defluoridation Studies}

To determine the influence of MPR activation method on water defluoridation, batch adsorption experiments were carried out overnight using a dosa of $2 \mathrm{~g}$ of each non-activated and activated MPR in $50 \mathrm{~mL}$ of fluoridated water with an initial fluoride concentration of $5 \mathrm{mg} / \mathrm{L}$. The agitation was done using Digital Grant Bio Shaker HY-51 machine. The samples were then filtered using a Whatman filter paper No. 41. The residues were kept aside and the filtrates were analyzed using fluoride ion selective electrode method to establish the percentage removal of fluoride ions. The activation method that gives an optimum defluoridation was 
then determined.

To find minimum amount of adsorbent giving optimum defluoridation, the best activated MPR was used in batch adsorption experiments to determine the efficacy of the different masses in removing fluoride ions from water. The selected masses in $\mathrm{g}$ of activated MPR were: $0.5,1,2,4,6,8$, 10 and 12. Each mass of the activated MPR was mixed with 50 $\mathrm{mL}$ of water containing initial fluoride ion concentration of 5 $\mathrm{mg} / \mathrm{L}$ in a plastic container. The content in the plastic container were agitated $(120 \mathrm{~min})$, filtered and fluoride ion concentration determination was performed as stated previously. The minimum amount of activated MPR giving optimum defluoridation was then determined.

To determine the minimun effective contant time, batch adsorption experiments were carried out using 9 plastic bottles each containing $50 \mathrm{~mL}$ of water with initial fluoride ions of 5 $\mathrm{mg} / \mathrm{L}$. About $8 \mathrm{~g}$ of the activated MPR were transferred into each of the plastic containers. Contact times tested were $5,10,15,30$, $45,60,75,90$ and 105 minutes. The remaining treatments to the contents in the plastic containers were as before.

The effect of initial fluoride ion concentration was also determined by batch adsorption experiments at fixed contact time (30 minutes), fixed amount of adsorbent $(8 \mathrm{~g})$ and at different initial fluoride ion concentration ranging from $4.0-60.0 \mathrm{mg} / \mathrm{L}$. The remaining treatments to the contents in the plastic containers were kept identical to previous experiments.
The effect of $\mathrm{pH}$ was found following the same procedure at fixed contact time (30 minutes), fixed amount of adsorbent (8 $\mathrm{g}$ ), fixed initial fluoride ion concentration $5 \mathrm{mg} / \mathrm{L}$, but $\mathrm{pH}$ was of fluoridated water was varied from 6 to 9 using $\mathrm{HCl}$ and $\mathrm{NaOH}$ solutions. The effective $\mathrm{pH}$ giving optimum defluoridation was then recorded.

The regeneration of the fluoride saturated activated MPR was performed in the same way as preparing caMPR in Section 2.2. Regeneration and reuse was performed several times.

\section{Results and Discussion}

\subsection{Characterization of MPR}

The X-Ray Diffractograms of both naMPR and caMPR are shown in Figures 1 and 2. The diffractograms of both naMPR and caMPR (Figures 1 and 2) revealed a poorly crystalline mineral. The diffractogram of naMPR (Figure 1) revealed the presence of fluoroapatite $\left(\mathrm{Ca}_{10}\left(\mathrm{PO}_{4}\right)_{6} \mathrm{~F}_{2}\right)$ as the major mineral apart from quartz $\left(\mathrm{SiO}_{2}\right)$. Pure apatite peak had almost $100 \%$ peak intensity with a value of 2.7863 arbitrary units. On the other hand, the diffractogram for caMPR (Figure 2) also reveal the presence of quartz $\left(\mathrm{SiO}_{2}\right)$ as the minor mineral and apatite mineral in form of hydroxyapatite $\left(\mathrm{Ca}_{10}\left(\mathrm{PO}_{4}\right)_{6}(\mathrm{OH})_{2}\right)$ and fluoroapatite $\left(\mathrm{Ca}_{10}\left(\mathrm{PO}_{4}\right)_{6} \mathrm{~F}_{2}\right)$ as the major minerals.

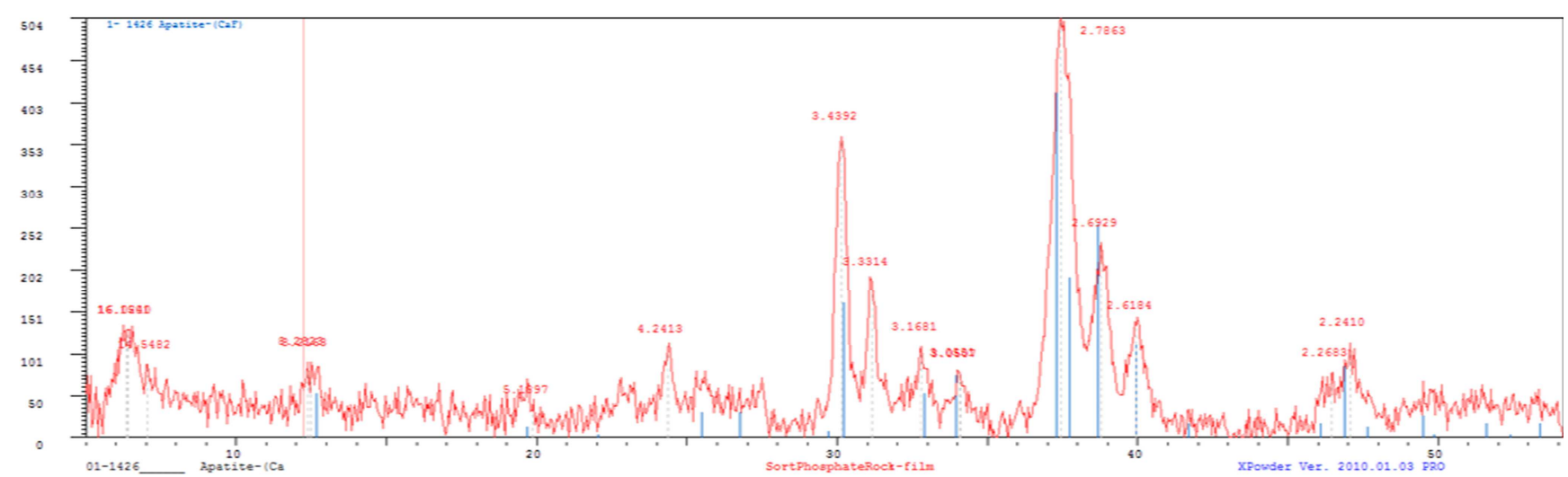

Figure 1. X-Ray Diffractogram of naMPR.

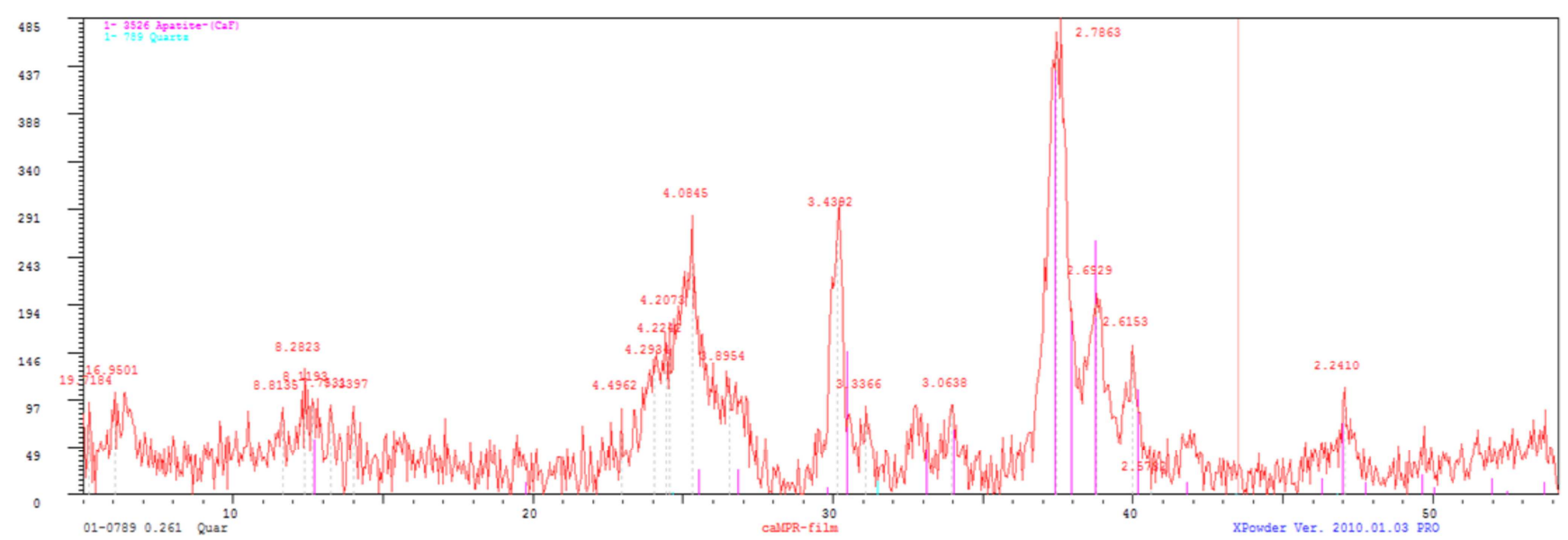

Figure 2. X-Ray Diffractogram of caMPR. 
Table 1. The XRF analysis results showing elemental composition in naMPR caMPR and taMPR.

\begin{tabular}{|c|c|c|c|c|c|c|c|}
\hline \multirow{2}{*}{ Component } & \multicolumn{3}{|c|}{ Percentage Weight (\%) } & \multirow{2}{*}{ Component } & \multicolumn{3}{|c|}{ Percentage Weight (\%) } \\
\hline & naMPR & caMPR & taMPR & & naMPR & caMPR & taMPR \\
\hline $\mathrm{CaO}$ & 44.47 & 39.78 & 33.76 & $\mathrm{SrO}$ & 0.78 & 0.76 & 1.17 \\
\hline $\mathrm{P}_{2} \mathrm{O}_{5}$ & 26.87 & 25.67 & 28.23 & $\mathrm{SO}_{3}$ & 0.59 & 0.46 & ND \\
\hline $\mathrm{SiO}_{2}$ & 8.67 & 20.41 & 19.84 & $\mathrm{BaO}$ & 0.21 & 0.17 & 1.22 \\
\hline $\mathrm{MgO}$ & 2.17 & 0.49 & 0.51 & $\mathrm{TiO}_{2}$ & 0.21 & 0.03 & 0.31 \\
\hline $\mathrm{Al}_{2} \mathrm{O}_{3}$ & 1.45 & 0.14 & 0.27 & $\mathrm{MnO}$ & 0.07 & 0.05 & 0.27 \\
\hline $\mathrm{Fe}_{2} \mathrm{O}_{3}$ & 1.39 & 0.25 & 2.92 & $\mathrm{ZrO}_{2}$ & 0.02 & ND & 0.04 \\
\hline $\mathrm{K}_{2} \mathrm{O}$ & 1.10 & 0.08 & 0.11 & $\mathrm{ZnO}$ & ND & 0.03 & 0.05 \\
\hline $\mathrm{Na}_{2} \mathrm{O}$ & 0.87 & 0.57 & 0.02 & LOI & 11.09 & 11.02 & 11.12 \\
\hline $\mathrm{Cl}$ & ND & 0.03 & ND & & & & \\
\hline
\end{tabular}

The XRF results in Table 1 show that, naMPR and caMPR had $\mathrm{CaO}$ and $\mathrm{P}_{2} \mathrm{O}_{5}$ in higher percentage weight values. The ratio of $\mathrm{Ca} / \mathrm{P}$ is 1.66 and 1.55 for naMPR and caMPR, respectively, whereas the $\mathrm{Ca} / \mathrm{P}$ ratio in taMPR was 1.20 . It is also revealed in Table 1 that naMPR, taMPR and caMPR contain $\mathrm{SiO}_{2}, \mathrm{MgO}$ and $\mathrm{Al}_{2} \mathrm{O}_{3}, \mathrm{Fe}_{2} \mathrm{O}_{3}$ also in slightly high percentage weight. Fluorine ion was not detected in XRF analysis because the Bruker XRF Spectrometer (Model S8 Tiger) can not measure the abundances of oxides of elements with atomic number less than 11 .

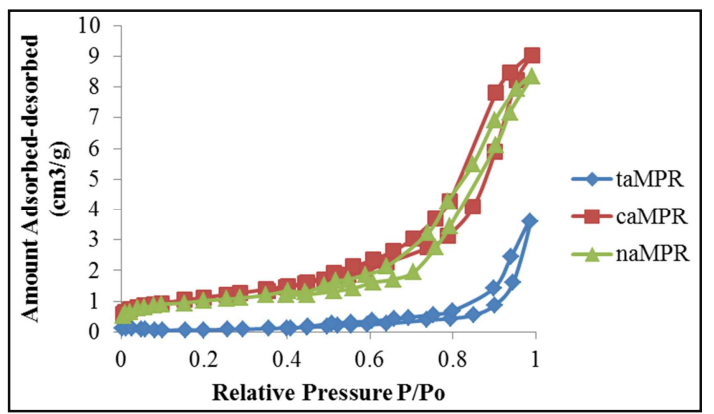

Figure 3. The nitrogen adsorption desorption isotherms for naMPR, taMPR and $c a M P R$.

As seen from this figure, the adsorption-desorption isotherms of naMPR, taMPR and caMPR at low P/Po less than 0.8 showed plateaus. At $\mathrm{P} / \mathrm{Po}$ above 0.8 , the adsorption-desorption isotherms showed sharp rise in nitrogen uptake. For taMPR the sharp rise started at $\mathrm{P} / \mathrm{Po}$ of 0.9 while for naMPR and caMPR started at $\mathrm{P} / \mathrm{Po}$ of 0.8 . The shapes of the isotherms clearly indicate type IV isotherms. The isotherms of naMPR, taMPR and caMPR also indicate the presence of hysteresis loops of type $\mathrm{H} 3$ at $\mathrm{P} / \mathrm{Po}$ greater than 0.4 .

The BET surface area for taMPR $\left(2.8 \mathrm{~m}^{2} / \mathrm{g}\right)$ was less than that for caMPR $\left(57.4 \mathrm{~m}^{2} / \mathrm{g}\right)$ and less than that for naMPR (45.6 $\mathrm{m}^{2} / \mathrm{g}$ ). It is also shown that, taMPR had average pore diameter of $109.6 \mathrm{~nm}$ indicative of macroporous type of pores whereas caMPR and naMPR had pore diameter of $13.9 \mathrm{~nm}$ and $9.7 \mathrm{~nm}$, respectively, indicative of mesoporosity. The total pore volume in taMPR $\left(0.08 \mathrm{~cm}^{3} / \mathrm{g}\right)$ was less than the total pore volume for caMPR $\left(0.20 \mathrm{~cm}^{3} / \mathrm{g}\right)$ and that for naMPR $\left(0.16 \mathrm{~cm}^{3} / \mathrm{g}\right)$.

\subsection{Results for Defluoridation Studies}

Results regarding the consequence of MPR activation methods on fluoride removal are shown in Figure 4. As seen in this figure, the highest fluoride ion removal (81.3\%) was obtained using caMPR. The naMPR gave a negative fluoride removal $(-30.5 \%)$, which means that the material bleeded fluoride ions into the tested water. Thermal activation method gave a material (taMPR) with very little fluoride removal (5.7\%). Thermal activation followed by chemical activation (tcaMPR) and vice versa (ctaMPR) did not improve the MPR fluoride ion removal. Thus, further defluoridation experiments were performed using caMPR.

Minimum dose of caMPR required for effective defluoridation was obtained by plotting percent $\mathrm{F}^{-}$removal as a function of caMPR dose as shown in Figure 5. As expected, increasing the caMPR dose increased the fluoride ion removal up to $87 \%$ with $8 \mathrm{~g}$. No further significant increase in fluoride ion removal was observed beyond $8 \mathrm{~g}$ of an adsorbent.

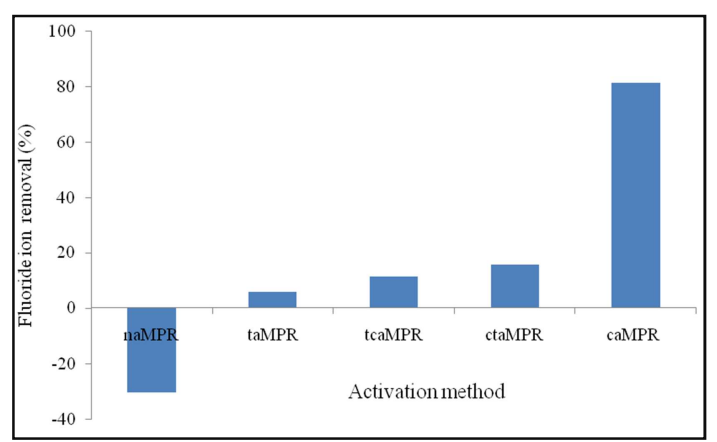

Figure 4. The influence of MPR activation method on fluoride ions removal (Conditions: adsorbent dose $=2 \mathrm{~g}$, initial fluoride ion concentration $=5.12$ $\mathrm{mg} / \mathrm{L}$, contact time $=$ overnight, batch volume $=50 \mathrm{ml}$ ).

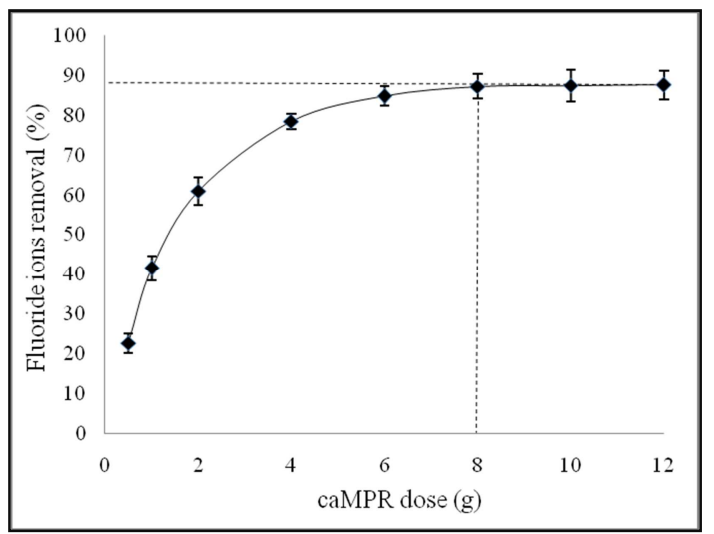

Figure 5. A plot of fluoride ion removal as a function of caMPR dose (Conditions: initial fluoride ion concentration $=5.02 \mathrm{mg} / \mathrm{L}$, contact time $=$ $120 \mathrm{~min}$, batch volume $50 \mathrm{ml}$ ). 
After finding out the best MPR activation method and the smallest adsorbent amount, it was of the essence to find out the shortest contact time for fluoride ions uptake. Figure 6 shows the defluoridation results using $8 \mathrm{~g}$ of the caMPR.

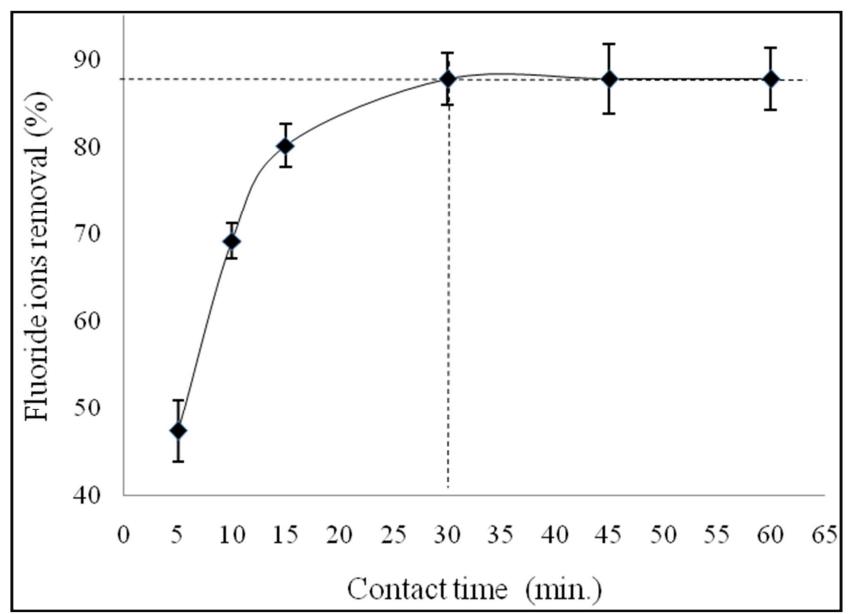

Figure 6. A plot of fluoride ion removal as a function of contact time ( $8 \mathrm{~g}$ caMPR, initial fluoride ion concentration $=5.0 \mathrm{mg} / \mathrm{L}$, batch volume $50 \mathrm{ml}$ ).

From Figure 6 one can conclude that $30 \mathrm{~min}$ is shortest contact time required for optimum fluoride ions removal.

Initial fluoride ion concentration is another important parameter investigated. The results for this experiment are shown in Figure 7. It is clearly seen from this figure that the efficacy of $8 \mathrm{~g}$ of caMPR is reduced as the initial fluoride ion concentration is increased. However, up to initial fluoride concentration of $12.4 \mathrm{mg} / \mathrm{L}, 8 \mathrm{~g}$ of caMPR can reduce fluoride ions to $\leq 1.5 \mathrm{mg} / \mathrm{L}$, which is within the highest WHO limit. Beyond $12.4 \mathrm{mg} / \mathrm{L}$ initial fluoride concentration, the remaining fluoride ions are above the recommended uppermost WHO concentration.

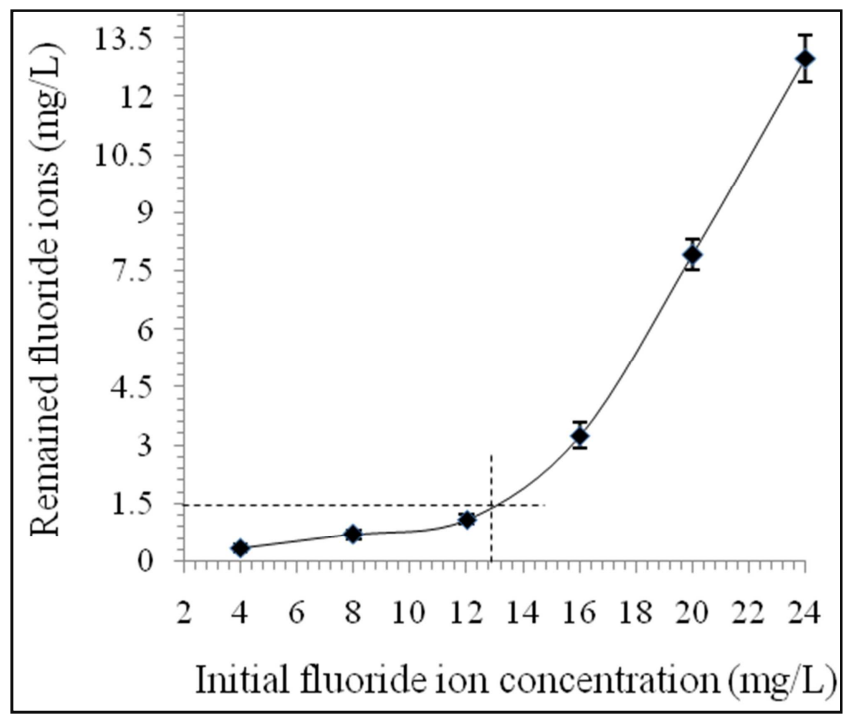

Figure 7. A plot of fluoride ion remained as a function of initial fluoride concentration $(8 \mathrm{~g}$ caMPR, contact time $=30 \mathrm{~min}$, batch volume $=50 \mathrm{ml})$.

Results for the influence of $\mathrm{pH}$ are shown in Figure 8. No significant change in fluoride ion removal at $\mathrm{pH}$ range from 6.0 to 7.2, however, there was a decrease in the extent of fluoride ions removal with increase in $\mathrm{pH}$ above 7.2 (Figure 8).

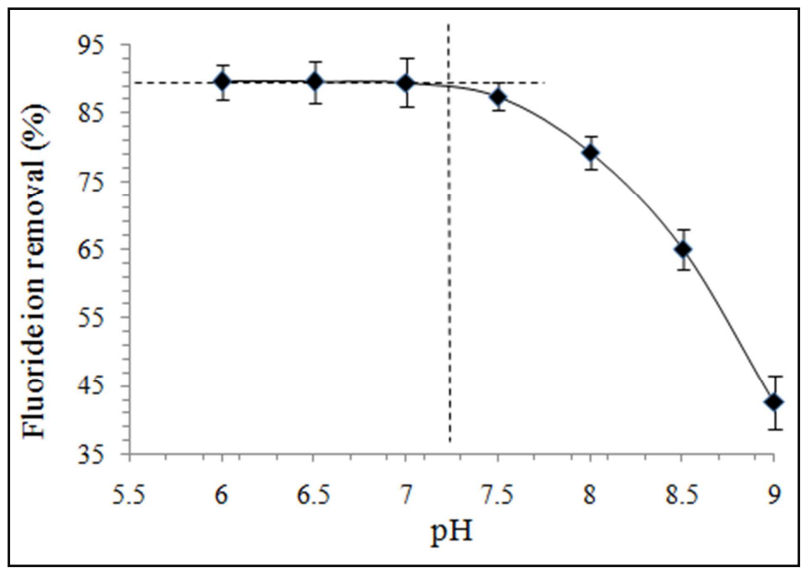

Figure 8. The effect of $p H$ on fluoride ions removal $(8 \mathrm{~g} c a M P R$, initial fluoride ion concentration $=5 \mathrm{mg} / \mathrm{L}$, contact time $=30 \mathrm{~min}$, batch volume $=$ $50 \mathrm{ml}$ ).

The environmental concern regarding production of sludge was also considered by testing the regeneration of an effective adsorbent from fluoride ion saturated caMPR. Figure 9 shows number of cycles of regeneration and the reuse of the regenerated caMPR. It is revealed from this figure that for cycles tested high fluoride removal was maintained.

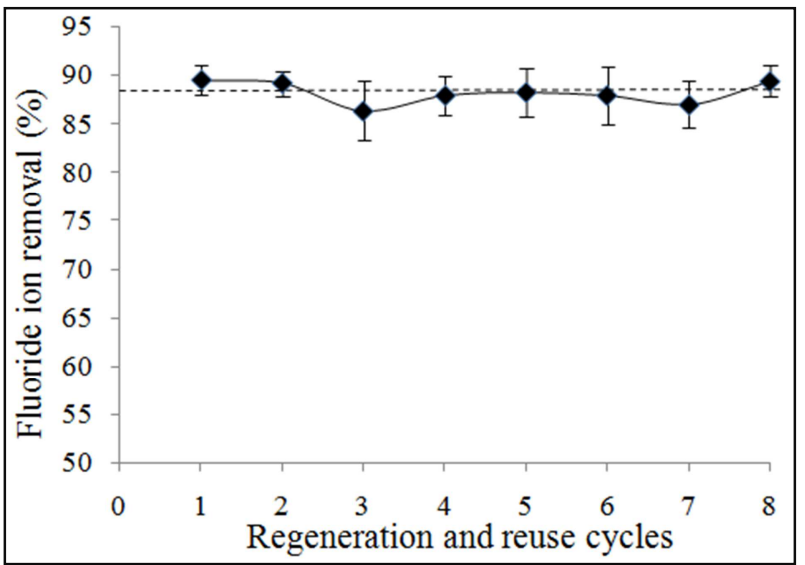

Figure 9. Cycles of regeneration and reuse of the regenerated caMPR ( $8 \mathrm{~g}$ regenerated caMPR, initial fluoride ion concentration $=5 \mathrm{mg} / \mathrm{L}$, contact time $=30 \mathrm{~min}$, batch volume $=50 \mathrm{ml}$ ).

\section{Conclusion}

The major chemical components of the non-activated and activated MPR are $\mathrm{CaO}, \mathrm{P}_{2} \mathrm{O}_{5}$ and $\mathrm{SiO}_{2}$. The main mineralogical components in non-activated $\mathrm{MPR}$ are fluoroapatite $\left(\mathrm{Ca}_{10}\left(\mathrm{PO}_{4}\right)_{6} \mathrm{~F}_{2}\right)$ and quartz $\left(\mathrm{SiO}_{2}\right)$ whereas the caMPR mainly contain apatites $\left(\mathrm{Ca}_{10}\left(\mathrm{PO}_{4}\right)_{6}(\mathrm{OH})_{2}\right.$, $\left.\mathrm{Ca}_{10}\left(\mathrm{PO}_{4}\right)_{6} \mathrm{~F}_{2}\right)$ and quartz $\left(\mathrm{SiO}_{2}\right)$. The caMPR and taMPR are mesoporous materials with type IV isotherms and hysteresis loop type H3. Moreover caMPR has BET surface area of 57.4 $\mathrm{m}^{2}$ which may be a factor for its effective fluoride ions adsorption. The minimum contact time required for optimum fluoride ion uptake by caMPR adsorption was found to be 30 
minutes. The caMPR material is effective in defluoridating water to WHO recommended levels up to initial fluoride concentration of $12.4 \mathrm{mg} / \mathrm{L}$ in a $\mathrm{pH}$ range from 6 to 7.2 . A saturated caMPR material can be regenerated using $1 \% \mathrm{NaOH}$ and reused several times. It can thus be concluded that the caMPR can serve as alternative adsorbent for the removal of fluoride ions from fluoridated water.

\section{References}

[1] Kashaigili J. J. (2010) Assessment of Groundwater Availability and its Current and Potential Use Impacts in Tanzania. Final Report Prepared for the International Water Management Institute, pp 1-58.

[2] Roy S. and Dass G. (2013) Fluorine Contamination in Drinking Water. Resour. Environ. 3: 53-58.

[3] Tiemann M. (2013) Fluoride in Drinking Water: A Review of Fluoridation and Regulations Issues: Report for Congress Congressional Research Services, pp 1-21.

[4] WHO (2004) Fluoride in Drinking-water. Background Document for Development of WHO Guidelines for Drinking-water Quality. World Health Organization: Geneva, pp. 1-7.

[5] WHO (1994) Fluorides and Oral Health. Report of a WHO Expert Committee on Oral Health Status and Fluoride Use. WHO Technical Report Series 846. WHO, Geneva, pp 1-34.

[6] Ghiglieri G., Balia R., Ogiano G., and Pittalis D. (2010) Prospecting for Safe (low fluoride) Groundwater in the Eastern African Rift Valley: the Arumeru District Northern Tanzania. Hydrol. Earth. Syst. Sci. 14: 1081-1091.

[7] Fawell J., Bailey K., Chilton J., Dahi E., Fewtrell L. and Magara Y. (2006) Fluoride in Drinking Water, World Health Organization. IWA Publishing, London, pp 1-134.
[8] Gumbo F. J. and Mkongo G. (1995) Defluoridation for Rural Fluoride Affected Communities in Tanzania. Proceedings of the 1st international workshop on fluorosis and defluoridation of water, Ngurdoto, Tanzania, pp 109-114.

[9] Feenstra L., Vasak L. and Griffioen J. (2007) Fluoride in Groundwater. Overview and Evaluation of Removal Methods, Report SP 2007-1. International Groundwater Resource Assessment Centre, Utrecht, Netherland, pp 1-21.

[10] Thole B. (2013) Ground Water Contamination with Fluoride and Potential Fluoride Removal Technologies for East and Southern Africa; Perspectives in Water Pollution, Ahmad I (Ed.), pp 65-91.

[11] Bjorvatn K. and Bårdsen A. (1995) Use of Activated Clay for Defluoridation of Water. Proceedings of the 1st International Workshop on Fluorosis and Defluoridation of Water, Ngurdoto, Tanzania, pp 49-55.

[12] Meenekshi and Maheshwari R. C. (2006) Fluoride in Drinking Water and its Removal, J. Hazard. Mater, pp 456-463.

[13] Kaseva E. M. (2006) Optimization of Regenerated Bone Char for Fluoride Removal in Drinking Water: A Case Study in Tanzania: J. Water Health, pp 139-147.

[14] Dahi E., Mtalo F., Njau B. and Bregnhj H. (1996) Defluoridation Using the Nalgonda Technique in Tanzania. Proceedings of the 2nd WEDC Conference, New Delhi, pp 266-268.

[15] Renuka, P. and Pushpanjal, K. (2013) Review on Defluoridation Technologies of Water. Int. J. Eng. Sci. 2: 8694.

[16] Mumtaz, N., Pandey, G. and Labhasetwar, P. K. (2014) Assessment of electrolytic process for water defluoridation. Int. J. Environ. Res. Public Health, pp 175-182.

[17] Khairnar M. R., Dodamani, A. S., Jadhav, H. C., Naik, R. G. and Deshmukh, M. A. (2015) Mitigation of Fluorosis - A Review. J. Clin. Diagn. Res. pp 5-9. 